\title{
Detection of Anaphylactic Reaction in the Percutaneously Sensitized Mouse Using the AW Method
}

\author{
Hiromi Kataoka, ${ }^{*}$ Yuki Shinohara, Tomoka Takatani, Akane Mizuta, Yoshimi Tsuda, Hisae Fukui, \\ Masanori SEMmA, and Yoshio ITO \\ Faculty of Pharmaceutical Sciences, Mukogawa Women's University, 11-68 Koshien Kyuban-cho, Nishinomiya, Hyogo \\ 663-8179, Japan. Received March 1, 1999; accepted June 7, 1999
}

\begin{abstract}
Anaphylactic reactions of mice sensitized percutaneously with 2,4-dinitrofluorobenzene (DNFB) were investigated by the AW method assay, which is a mouse anaphylactic model using the abdominal wall as the site for induction with either 2,4-dinitrophenyl (DNP)-human serum albumin or anti-mouse IgE antibody and then estimation of the response. DNP-specific and IgE-dependent anaphylactic reaction after contact sensitization with DNFB could be induced and detected by the abdominal wall (AW) method assay in both groups with and without previous ear challenge with DNFB. Thus, the anaphylactic reaction in the group of twice-contact with $0.5 \%$ DNFB was observed on the 9th day from the sensitization (5th day from the ear challenge), and the reaction in the group of a single contact with $0.5 \%$ DNFB was observed $10 \mathrm{~d}$ after sensitization. The DNP-specific anaphylactic reaction was observed earlier than the 10th day with higher doses of DNFB.

As for the mice of the former twice-contact group, the first and second characteristic ear swelling responses appeared within $1-6 \mathrm{~h}$ and $2 \mathrm{~d}$ of the ear challenge, respectively, and small swelling was observed $7 \mathrm{~d}$ after the challenge.

It is suggested that Th1 and Th2 cells are activated at the almost same time, in other words, the preparation for both cell-mediated and humoral immunity could be accomplished to function, in vivo by a single percutaneous sensitization with DNFB.
\end{abstract}

Key words abdominal wall method (AW method); anaphylactic reaction; percutaneous sensitization; delayed-type hypersensitivity (DTH); contact hypersensitivity reaction (CHR)

Allergy is one of the most critical medical problems in the present world. Of allergies, both immediate type hypersensitivity (type I) such as anaphylaxis, food allergy, hay fever, asthma, or drug allergy, and delayed-type hypersensitivity (DTH) (type IV) such as contact dermatitis or tuberculintype hypersensitivity reaction occur frequently. It is also an important problem whether or not an anaphylaxis occurs in one suffering from contact hypersensitivity when exposed to the same hapten coupled to carrier proteins. The best treatment for allergy is to avoid the allergen for both the immediate and delayed-type hypersensitivity. Also research into antiallergic drugs and the search for anti-allergic substances in foods are important. Previously, we reported an original and simple mouse anaphylactic model using the abdominal wall (AW) as the site for both the induction and estimation (AW method), for the purpose of the detection of the allergens in foods or research into anti-allergic substances. ${ }^{1-3)}$

Classically, type I is humoral immunity depending on the $\mathrm{IgE}$ antibody. The resulting release of histamine, serotonin, leukotorienes, and other chemical mediators by IgE-sensitized mast cells produces an acute vasodilation and several inflammatory reactions (for example, an increase in vascular permeability or swelling). On the other hand, type IV is called cell-mediated immunity because the response cannot be transferred from a sensitized individual to a normal individual by serum, but can be transferred by $\mathrm{T}$ cells.

Helper T (Th) cells can be subdivided into two major categories, Th1 and Th2, depending on the abilities to secrete cytokines. IgE and IgG1 secretion in mouse are controlled by only Th2 cells. Th1 is mainly responsible for the induction of DTH. It is commonly accepted that the dominance of either the cell-mediated or humoral immunity depends on the balance of Th1 and Th2. ${ }^{4-6)}$
However, several DTH reactions deviate from this definition. It has been reported that although the contact hypersensitivity reaction (CHR) is a cell-mediated reaction, the CHR may contain elements of humoral immunity, because reaginic antibody was produced within 1 week of painting with picryl chloride ${ }^{7)}$ and mast cells participated in the reaction. ${ }^{8)}$ Moreover, it has recently been reported that hapten-specific IgE was induced by repeated contact application of 2,4-dinitrofluorobenzene (DNFB) to the ears of mice. ${ }^{9)}$

Ray et al. have also reported that antigen-specific and $\mathrm{IgE}$ mediated CHR was elicited by epicutaneous challenge (contact) with DNFB, because mice passively sensitized with monoclonal mouse anti-2,4-dinitrophenyl (DNP) IgE responded to the percutaneously administered DNFB. ${ }^{10)}$ Mouse CHR has been reported to show a two-phase reaction, the early phase occurred at about $1 \mathrm{~h}$ and the late phase about 48 $\mathrm{h}$ after the percutaneous challenge. This late phase is the reason why CHR is called a delayed-type hypersensitivity. It is reported that the components of the early phase involve not only the vasoactive amine, serotonin $(5-\mathrm{HT})$, but also T-cells and mast cells. ${ }^{11,12)}$ Furthermore, Lei et al. reported that the early phase could be transferred by immune sera, but the reaction was not mediated by IgE. ${ }^{13,14)}$ The difference between the early and late phase has been shown to be related to Tcells of different phenotype. ${ }^{15,16)}$

Taken together, it is strongly suggested that $\operatorname{IgE}$ participates in the late phase but not early phase of T-cell-mediated immune responses such as CHR.

In the present study, we investigated whether an antigenspecific and IgE-dependent anaphylactic reaction in the percutaneously sensitized mice could be detected by the AW method assay. 


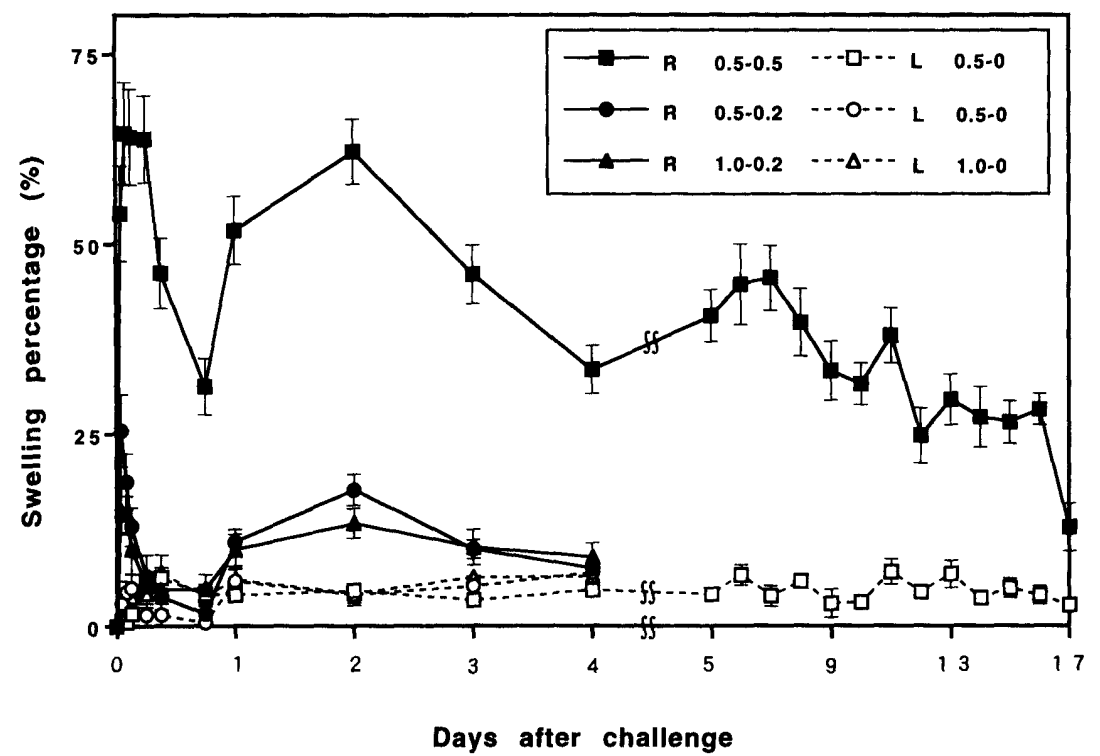

Fig. 1. Time Course and Dose-Response of Ear Swelling Percentage

Mice were sensitized with $0.1 \mathrm{ml}$ of DNFB in acetone-olive oil $(4: 1)(\mathbf{Q}, \square, \boldsymbol{\bullet}$, and $0.0 .5 \% ; \Delta$ and $\triangle, 1.0 \%)$ to the shaved dorsal skin on day 0 . Four days after sensitization, the mice were challenged on the right ear with $0.02 \mathrm{ml}$ of DNFB in acetone olive oil $(4: 1)(\mathbf{\square}, 0.5 \%$; and $\mathbf{\Lambda}, 0.2 \%)$. Acetone-olive oil $(4: 1)$ as a vehicle for DNFB solution was also painted to the left ear of the sensitized mice (open symbols). Ear thickness was measured with a Peacock Dial Thickness Gauge. Each symbol and bar of the ear swelling percentage represent the mean \pm S.E. for $15-24$ mice $(1 \mathrm{~h}-4 \mathrm{~d})$ or 10 mice $(5 \mathrm{~d}-17 \mathrm{~d})(\square$ and $\square)$, or $4-8$ mice $(-O, \mathbf{\Lambda}$, and $\Delta)$. Statistical analyses were performed by analysis of variance, followed by Fisher's PLSD test. all points from $1 \mathrm{~h}$ to $16 \mathrm{~d}, p<0.001 ; 17 \mathrm{~d}, p<0.006 ;-1 \mathrm{~h}$ and $2 \mathrm{~d}, p<0.001 ; 2 \mathrm{~h}, p<0.005 ; 3 \mathrm{~h}, 1 \mathrm{~d}$, and $3 \mathrm{~d}, p<0.05 ; \mathbf{\Lambda}: 1 \mathrm{~h}$ and $2 \mathrm{~h}, p<0.001 ; 2 \mathrm{~d}, p<0.002$.

\section{MATERIALS AND METHODS}

Animals Male ddY mice (SPF, 5 weeks old) were purchased from Japan SLC Co. (Hamamatsu). These animals were maintained under a constant temperature $\left(24 \pm 2{ }^{\circ} \mathrm{C}\right)$ and were fed commercial laboratory diet (CE-2, Clea Japan, Tokyo) and tap water ad libitum.

Reagents The following reagents were used in the present study: DNFB (Nacalai Tesque, Inc., Osaka, Japan); Evans blue and acetone (Wako Pure Chemical Industries, Ltd., Osaka, Japan); 2,4-dinitrophenyl-human serum albumin (DNP-HSA) (Sigma Chemical Co., St. Louis, MO, U.S.A.); and sheep polyclonal anti-mouse IgE antibody (The Binding Site Ltd., England); olive oil (The Japanese Pharmacopoeia grade, Maruishi Pharmaceutical, Co., Japan).

DNFB-Induced CHR Mice were sensitized with $0.1 \mathrm{ml}$ of 0.5 or $1.0 \%$ DNFB in acetone-olive oil $(4: 1)$ to the shaved dorsal skin on day 0 . Four days later, the mice were challenged on the right ear with 0.5 or $0.2 \%$ DNFB in acetone-olive oil $(4: 1)(0.02 \mathrm{ml} / \mathrm{ear})$. As a control, the left ear was painted with acetone-olive oil $(4: 1)$ alone $(0.02 \mathrm{ml} / \mathrm{ear})$. Ear thickness was measured with a Peacock Dial Thickness Gauge (Ozaki, Japan) before and after the challenge, and the difference in thickness was calculated. The degree of the respective right and left ear swelling was expressed as follows:

$$
\text { swelling percentage }(\%)=\left(E_{\mathrm{t}}-E_{0}\right) / E_{0} \times 100
$$

where $E_{0}$ and $E_{\mathrm{t}}$ represent the ear thickness before and after challenge. The significant differences were compared with the swelling percentage between the right ear and the left.

Anaphylactic Reaction Assays (AW Method) Mice were sensitized with $0.1 \mathrm{ml}$ of DNFB $(0.2,0.5,2.0$, or $5.0 \%)$ in acetone-olive oil $(4: 1)$ to the shaved dorsal skin on day 0 . Four days after sensitization, the mice were painted with $0.5 \%$ DNFB in acetone-olive oil $(4: 1)(0.02 \mathrm{ml} / \mathrm{ear})$ or not painted. Anaphylactic reaction of these DNFB-sensitized mice was assayed by the AW method as described previously. ${ }^{1,2)}$ Briefly, mice to be tested were injected $0.1 \mathrm{ml}$ of $1 \%$-Evans blue dye intravenously, and anesthetized with ether. The skin of the abdomen of the mice was detached without injury to the abdominal wall. Five minutes after injection of the dye, DNP-HSA $(0.2 \mathrm{mg} / \mathrm{ml})$ or 10 -fold diluted polyclonal anti-mouse $\operatorname{IgE}$ antibody was administered on the abdominal wall ( $50 \mu \mathrm{l} / \mathrm{site})$. Seven minutes after challenge, the abdominal wall of the mice was removed, and the diameter of the blue area was measured and assigned a vascular permeability value (VPV); $\mathrm{VPV}=0, x<1.5 ; \mathrm{VPV}=25$, $1.5 \leqq x<4.5 ; \mathrm{VPV}=50,4.5 \leqq x<7.5 ; \mathrm{VPV}=75,7.5 \leqq x<12.5$; and $\mathrm{VPV}=100,12.5 \leqq x$; where $x$ indicates the mean of long and short site of diameter $(\mathrm{mm})$.

Statistical Analysis Statistical analysis was performed by analysis of variance, followed by Fisher's Protected Least Significant Difference (PLSD) test. Each vascular permeability value (VPV) or ear swelling percentage represents the mean \pm S.E. Asterisks indicate significant differences from the control group (***, $p<0.001 ; * *, p<0.005$; and $*, p<$ $0.05)$.

\section{RESULTS AND DISCUSSION}

In the first experiment, we examined whether the mice of the ddY strain could elicit CHR induced by DNFB. The mice were sensitized percutaneously with 1.0 or $0.5 \%$ DNFB in acetone-olive oil $(4: 1)$ on day 0 . Four days after sensitization, the mice were challenged by painting with 0.5 or $0.2 \%$ DNFB in acetone-olive oil $(4: 1)$ on the right ear. Time course and dose dependence of the ear swelling response in the ddY strain mice are shown in Fig. 1. The ear swelling was enhanced by a dose of $0.5 \%$ DNFB solution in both sensitization and challenge. When DNFB sensitized mice were 
challenged with $0.2 \%$ DNFB solution, a rapid increment of the ear thickness occurred with a peak at $1 \mathrm{~h}$ after the challenge, well known as an early phase phenomenon. In contrast, when the mice were challenged with $0.5 \%$ DNFB, the early phase persisted for $6 \mathrm{~h}$. Significant $(p<0.001)$ changes in the ear thickness at multiple times were observed from $1 \mathrm{~h}$ to $16 \mathrm{~d}$ after the challenge. The characteristic ear swelling of the late phase appeared $2 \mathrm{~d}$ after challenge, followed by a small amount of swelling observed about $7 \mathrm{~d}$ after the challenge.

In the second section, experiments were undertaken to examine by the AW method assay, whether percutaneously sensitized mice with DNFB could induce an antigen-specific and IgE-dependent anaphylactic reaction. The experiments were divided into two groups of the $0.5 \%$ DNFB-sensitized mice which were challenged by the AW method assay either with previous ear challenge (SC-group) or without it (Sgroup) as shown in Fig. 2. Figure 3 shows the results of the AW method assay with DNP-HSA or polyclonal anti-mouse IgE antibody for both groups. The antigen-specific anaphylactic reaction by the AW method assay in the SC-group was observed on the 9th day after the sensitization (5th day from

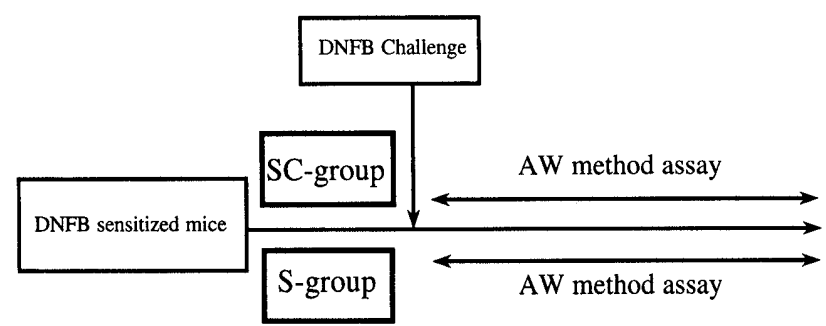

Fig. 2. Experimental System of the AW Method Assay in the Percutaneously Sensitized Mouse

DNFB sensitized mice were challenged by the DNP-HSA or polyclonal anti-mouse $\mathrm{IgE}$ antibody either with previous ear challenge (SC-group) or without it (S-group). the challenge). Interestingly, the anaphylactic reaction in the S-group was observed on the 10th day after the sensitization. Moreover, the anaphylactic reaction for both groups of mice that were challenged with polyclonal anti-mouse $\operatorname{IgE}$ antibody instead of DNP-HSA on day 14, was significantly different from the level of normal control mice.

In the S-group, the dose dependence of the antigen-specific anaphylactic reaction was examined independently of the above experiment for periods of 8 to $11 \mathrm{~d}$ after sensitization as shown in Fig. 4. Within 24 h, 18 of 32 mice that were sensitized with $5 \%$ DNFB died (the death percentage, $56.3 \%$ ). The anaphylactic reactions of the surviving mice and the $2 \%$ DNFB sensitized mice were observed on the 8 th day after the sensitization. On the other hand, the anaphylactic reaction of the mice sensitized with $0.2 \%$ DNFB was not significantly different from the normal control mice in the period from the 8th day to the 11 th after the sensitization. It is suggested that in the induction of the anaphylactic reaction by percutaneous sensitization, not only the number of times of exposure but also the doses of DNFB are important factors. Bacci et al. reported, using BALB/c mice, ${ }^{17)}$ that a high dose (conventional sensitizing dose, $0.5 \%$ ) of DNFB was deleterious for epidermal Langerhans' cells, compared to a low dose (optimal sensitizing dose, $0.004 \%$ ). Moreover, they reported, when high doses of DNFB were applied epicutaneously, only dermal antigen-presenting cells (APCs) appear to matter in the CHR. Our present results suggested that the dermal APCs may strongly participate in not only cell-mediated immunity but also humoral immunity, because the DNPspecific anaphylactic reaction was observed a day earlier with higher doses of DNFB. As for the induction of the anaphylactic reaction, it is presumed that because all of the administrated DNFB of high doses can not bind instantly to carrier proteins on the painted site, the residual free DNFB on the site may bind to the proteins gradually, therefore, sev-

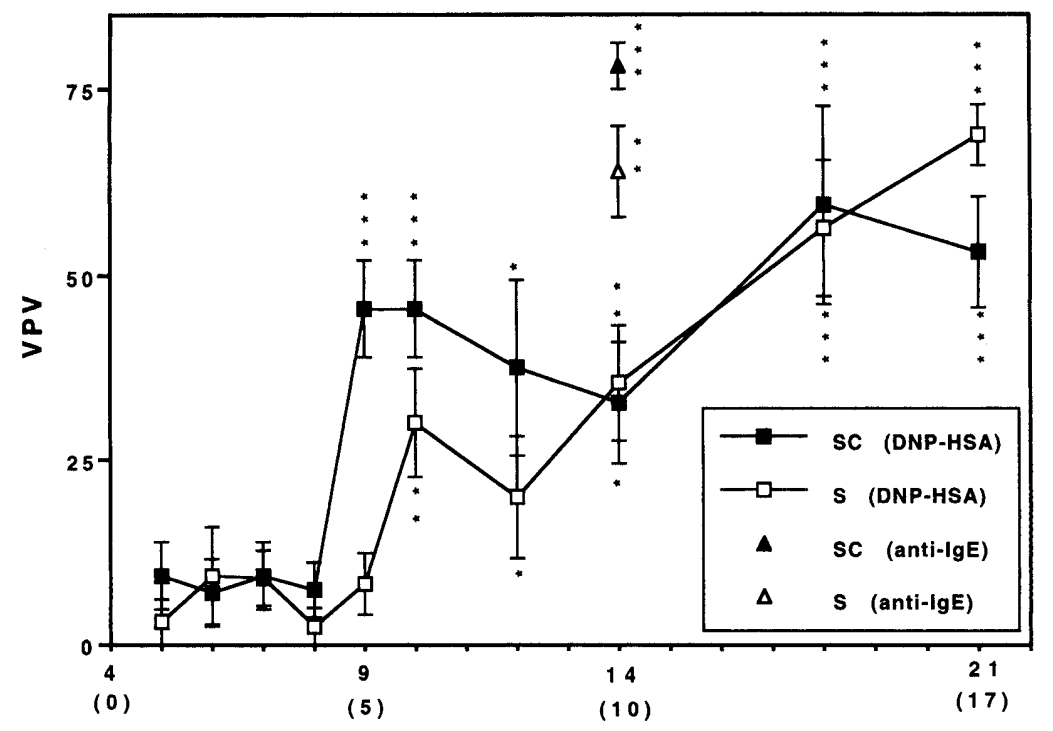

Days after sensitization (challenge)

Fig. 3. Antigen-Specific and IgE-Dependent Anaphylactic Reaction by AW Method Assay

Mice sensitized with $0.1 \mathrm{ml}$ of $0.5 \%$ DNFB were divided into two experimental groups as in Fig. 2. Four days after sensitization, the SC-group ( $\mathbf{\square}$ and $\mathbf{\Delta})$ was challenged in the ear with $0.5 \%$ DNFB in acetone-olive oil $(4: 1)$, and the S-group $(\square$ and $\triangle)$ was not challenged in the ear. The mice of both groups were challenged on the abdominal wall with DNP-HSA $(0.2 \mathrm{mg} / \mathrm{ml}, 10 \mu \mathrm{g} / 50 \mu \mathrm{l} / \mathrm{site})$, at the indicated days after sensitization. The VPV (vascular permeability value) of all the normal control mice exhibited zero ( $n=1-8)$. In another experiment, mice were challenged with polyclonal anti-mouse IgE antibody ( $50 \mu \mathrm{l} / \mathrm{site})$ instead of DNP-HSA, $14 \mathrm{~d}$ after $0.5 \%$ DNFB sensitization. The VPV of normal control mice was $34.6 \pm 6.0$. Each VPV represents the mean \pm S.E. for $8-13$ mice. Statistical analyses were as Fig. $1(* * *, p<0.001 ; * *, p<0.005 ; *, p<0.05)$. Asterisks indicate significant differences from normal control mice. 


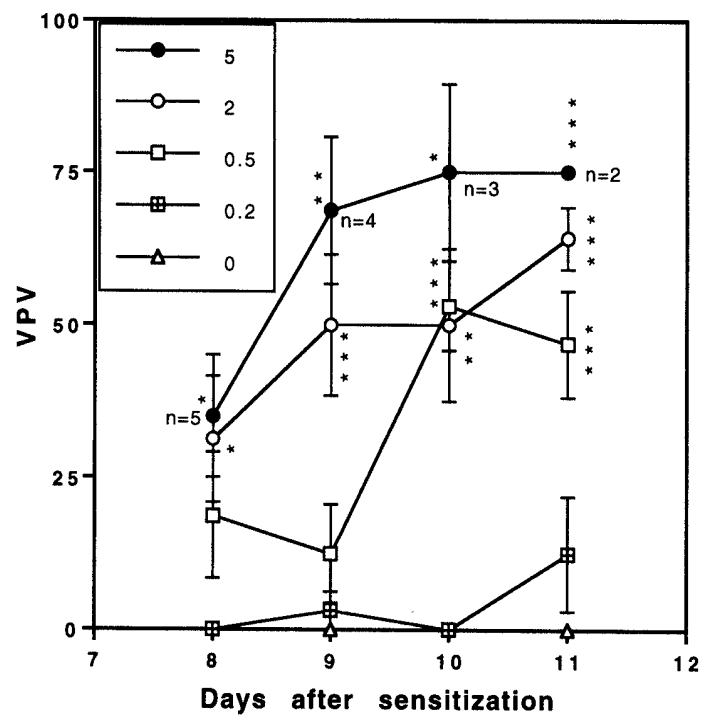

Fig. 4. Dose-Dependence of Anaphylactic Reaction by a Single Percutaneous Sensitization with DNFB

Mice were sensitized with DNFB of several concentrations $(0.2,0.5,2.0$, and $5.0 \%$ $0.1 \mathrm{ml}$ ). The experiment shown in Fig. 4 was examined independently from the experiment in Fig. 3. The mice were challenged on the abdominal wall with DNP-HSA $(0.2$ $\mathrm{mg} / \mathrm{ml}, 10 \mu \mathrm{g} / 50 \mu \mathrm{l} / \mathrm{site}$ ), at 8 to $11 \mathrm{~d}$ after sensitization. Each VPV represents the mean \pm S.E. for $7-8$ mice, unless otherwise indicated. Eighteen of 32 mice that were sensitized with $5 \%$ DNFB died within $24 \mathrm{~h}$. Statistical analyses were as Fig. $1(* * *, p<$ $0.001 ; * *, p<0.005 ; *, p<0.05$ ). Asterisks indicate significant differences from normal control mice.

eral immunity systems are activated continuously.

Consequently, these results indicate that the DNP-specific and IgE-dependent immediate hypersensitivity reaction that characterizes the increment of vascular permeability was certainly induced in the percutaneously sensitized mice with DNFB. If Thl becomes predominant, the cell-mediated immunity becomes predominant; in other cases Th2 is dominant and humoral immunity becomes predominant. Generally, it is thought that the balance of Th1 and Th2 is determined by the difference of the structure, dose, and administration route of the antigen and so on. Further studies are needed to elucidate the relationship between the doses of the DNFB and the balance of Th1 and Th2.

From these present results, it is suggested that cell-mediated and humoral immunity were initiated at the almost same time by only a single contact on the skin with DNFB, in a dose-dependent manner.

In conclusion, the DNP-specific and IgE-dependent anaphylactic reaction in the mice percutaneously sensitized with DNFB could be detected by the AW method assay. Furthermore, it is suggested that Th1 and Th2 are activated at the almost same time by a single percutaneous sensitization of DNFB which is a strong contact sensitizer, and that the preparation of both cell-mediated and humoral immunity could be accomplished to function in the ddY mouse, in vivo.

\section{REFERENCES}

1) Kataoka H., Tsuda A., Tsuda Y., Baba A., Yoshida H., Hirasawa R., Tobimatsu Y., Nishiguchi M., Semma M., Ito Y., Biol. Pharm. Bull., 20, 714-716 (1997).

2) Kataoka H., Tsuda A., Tsuda Y., Baba A., Yoshida H., Fukui H., Nishiguchi M., Tanaka K., Semma M., Ito Y., Jpn. J. Toxicol. Environ. Health., 44, 277-288 (1998).

3) Fukui H., Kataoka H., Semma M., Ito Y., Takagaki Y., J. Food Hyg. Soc. Japan, 39, 251-255 (1998)

4) Yamashita N., Sakane T., Igaku No Ayumi, 180, 85-89 (1997).

5) Nishimura T., Molecular Medicine, 1996-1997, s33, 156-168 (1996).

6) Kashiwamura S., Nakanishi K., Shinka S., Clinical Immunology, 27, (Suppl. 16), 325-335 (1995).

7) Thomas W. R., Asherson G. L., Watkins M. C., J. Exp. Med., 114, 1386-1390 (1976).

8) Thomas W. R., Vardinon N., Watkins M. C., Asherson G. L., Immunology, 39, 331-336 (1980).

9) Nagai H., Matsuo A., Hiyama H., Inagaki N., Kawada K., J. Allergy Chin. Immunol., 100, S39-44 (1997).

10) Ray M. C., Tharp M. D., Sullivan T. J., Tigelaar R. E., J. Immunol., 131, 1096-1102 (1983)

11) Van Loveren H., Meade R., Askenase P. W., J. Exp. Med., 157, 1604 1617 (1983).

12) Van Loveren H., K-Kops S., Askenase P. W., Eur. J. Immunol,, 14, $40-47(1984)$

13) Lei H.-Y., Huang K.-J., Shen C.-L., Huang J.-L., J. Immunol., 143, $432-438$ (1989).

14) Lei H.-Y., Wang J.-Y., Chang T.-T., Wang C.-C., Clin. Exp. Immunol., 83, 210-214 (1991).

15) Van Loveren H. V., Kato K., Meade R., Green D. R., Horowitz M., Ptak W., Askenase P. W., J. Immunol., 133, 2402-2411 (1984).

16) Ishii N., Takahashi K., Nakajima H., Tanaka S., Askenase P. W., J. Invest. Dermatol., 102, $321-327$ (1994).

17) Bacci S., Alard P., Dai R., Nakamura T., Streilein J. W., Eur. J. Immunol., 27, 442-448 (1997). 